\title{
GUEST HOUSE HUMA BETANG INDAH DI BUNTOK
}

\author{
Yuztira Wanagita \\ Program Studi Teknik Arsitektur Fakultas Teknik Universitas Lambung Mangkurat \\ yuztirawanagita@icloud.com \\ Dr. Irwan Yudha Hadinata \\ Program Studi Teknik Arsitektur Fakultas Teknik Universitas Lambung Mangkurat \\ irwan.yudha@ulm.ac.id
}

\begin{abstract}
ABSTRAK
Guest house adalah sebuah bangunan yang ditujukan untuk penginapan. Permasalahan utama dalam perancangan Guest House Huma Betang Indah di Buntok adalah bagaimana membangun bangunan yang dapat serasi dengan alam melalui budaya dayak yang nyaman untuk pengguna. Dengan pendekatan analogi langsung sebagai metode desain, perancangan guest house ini memiliki objek amatan berupa rumah betang. Rumah betang merupakan rumah adat suku dayak yang memiliki ikatan kuat dengan alam. sehingga untuk menerapkan prinsip-prinsip rumah betang ke guest house digunakan konsep Analogi arsitektur. Sebuah guest house yang dapat memberikan pengalaman baru bagi pengunjung dengan menyediakan berbagai elemen alami didalamnya. keluarga.
\end{abstract}

Kata Kunci: Guest House, Dayak, Rumah Betang, Analogi Langsung

\section{ABSTRACT}

Guest house is a building built for accomodation purpose. The main problem in designing the Huma Betang Indah Guest House in Buntok is how the building can harmonize with nature through dayak culture which is comfortable for the guest. With the direct analogy approach as a design method, the design of this guest house has an object of observation in the form of a rumah betang. Rumah betang is a traditional Dayak tribe house that has strong ties with nature. Thus to apply the principles of rumah betang to the guest house the concept of Analogy architecture is used. A guest house that can provide new experiences for guests by providing various natural elements in it.

Keywords: Guest House, Dayak, Rumah Betang, Direct Analogy

\section{PENDAHULUAN}

Kota Buntok merupakan ibukota Barito Selatan, Kalimantan Tengah. Kabupaten Barito Selatan memiliki luas wilayah $8.830 \mathrm{~km}^{2}$ dan berpenduduk sebanyak 131.987 jiwa (Sensus Penduduk Indonesia 2015).

Kota Buntok berada di pesisir Sungai Barito dan menghubungkan Kota Palangka Raya dengan Kabupaten-Kabupaten yang berada di daerah aliran Sungai Barito seperti Barito Utara, Barito Timur hingga Kabupaten di Kalimantan Selatan. Dulunya kota ini cukup terpencil namun sekarang sudah dilewati jalan Trans Kalimantan poros tengah yang menghubungkan Provinsi Kalimantan yang lainnya dengan Kalimantan Tengah.

Terbukanya akses Jalan Trans Kalimantan poros Tengah menjadikan Kota Buntok berpotensi menjadi kota transit. Kota transit merupakan kota yang dapat berperan sebagai tempat singgah dan jalur penghubung antar satu kota dengan kota lainnya. Kota transit juga dicirikan oleh kondisi aktivitas sekitar wilayahnya untuk mendukung fungsi dalam sistem internal wilayah yang lebih luas. Selain akses Jalan Trans Kalimantan poros Tengah, Kota 
Buntok juga dapat diakses melalui udara dan air. Fasilitas transportasi yang tersedia di Kota Buntok berupa Bandar Udara Sanggu, Terminal Bus AKAP, Pelabuhan Pasar Lama dan Pelabuhan Jelapat.

Akibat identitas Kota Buntok sebagai kota penghubung antara satu kota dengan kota lainnya, menjadikan Kota Buntok ramai dikunjungi wisatawan. Berdasarkan hasil survei wisatawan yang datang ke Kota Buntok adalah pedagang asal Hulu Sungai, keperluan bisnis batu bara dan kelapa sawit, tamu pemerintah dan saat diadakan acara-acara besar yang di Kota Buntok seperti off road. Banyaknya wisatawan yang datang mengakibatkan tingginya permintaan akan keberadaan penginapan.

Saat ini pilihan penginapan yang ada di Kota Buntok tidak menyediakan fasilitas yang memenuhi kriteria kenyamanan untuk pengunjung. Menurut Dodi Afrinaldi, Okky Sulastio, M. Rachman dan Tecky H. Kriteria kenyamanan ruang dibagi menjadi hubungan antar ruang serta kenyamanan ruang gerak, kenyamanan kondisi udara di ruangan (indoor air quality), kenyamanan fisik (ergonomic), kenyamanan kebisingan dan tingkat getar (accoustic comfort), kenyamanan pandangan (visual comfort) dan kenyamanan inderawi (sensing comfort).

Berikut tinjauan kenyamanan fasilitas beberapa penginapan yang ada di Kota Buntok:

Table 1 Tinjauan Kenyamanan Fasilitas Penginapan di Buntok

\begin{tabular}{|c|c|c|c|c|}
\hline \multirow[b]{2}{*}{$\begin{array}{l}\text { Nama } \\
\text { Banguna } \\
\mathbf{n}\end{array}$} & \multicolumn{4}{|c|}{ Kriteria Kenyamanan Bangunan } \\
\hline & Sirkulasi & $\begin{array}{l}\text { Kondisi } \\
\text { udara } \\
\text { dalam } \\
\text { ruangan }\end{array}$ & $\begin{array}{l}\text { pandang } \\
\text { an }\end{array}$ & $\begin{array}{l}\text { Tingkat } \\
\text { getar } \\
\text { dan } \\
\text { kebising } \\
\text { an }\end{array}$ \\
\hline $\begin{array}{l}\text { Hotel } \\
\text { Mulya } \\
\text { Kencana }\end{array}$ & $\begin{array}{l}\text { Bangunan } \\
\text { berlantai } \\
\text { tiga } \\
\text { dengan } \\
\text { tangga } \\
\text { selebar } \\
1.5 \mathrm{M}\end{array}$ & $\begin{array}{l}\text { Penghawa } \\
\text { an buatan } \\
\text { tidak tidak } \\
\text { berfungsi } \\
\text { dengan } \\
\text { baik }\end{array}$ & $\begin{array}{l}\text { Hotel } \\
\text { Berada } \\
\text { di jalan } \\
\text { utama }\end{array}$ & $\begin{array}{l}\text { Tingkat } \\
\text { kebising } \\
\text { an tinggi }\end{array}$ \\
\hline $\begin{array}{l}\text { Hotel } \\
\text { Afiat } \\
\text { Jaya }\end{array}$ & $\begin{array}{l}\text { Kamar } \\
\text { langsung } \\
\text { menghada } \\
\text { p halaman } \\
\text { terbuka } \\
\text { dan } \\
\text { dihubungk } \\
\text { an oleh } \\
\text { selasar }\end{array}$ & $\begin{array}{l}\text { Penghawa } \\
\text { an buatan }\end{array}$ & $\begin{array}{l}\text { Secara } \\
\text { visual } \\
\text { fasad } \\
\text { banguna } \\
\mathrm{n} \text { tidak } \\
\text { terawat }\end{array}$ & $\begin{array}{l}\text { Tingkat } \\
\text { kebising } \\
\text { an tinggi }\end{array}$ \\
\hline
\end{tabular}

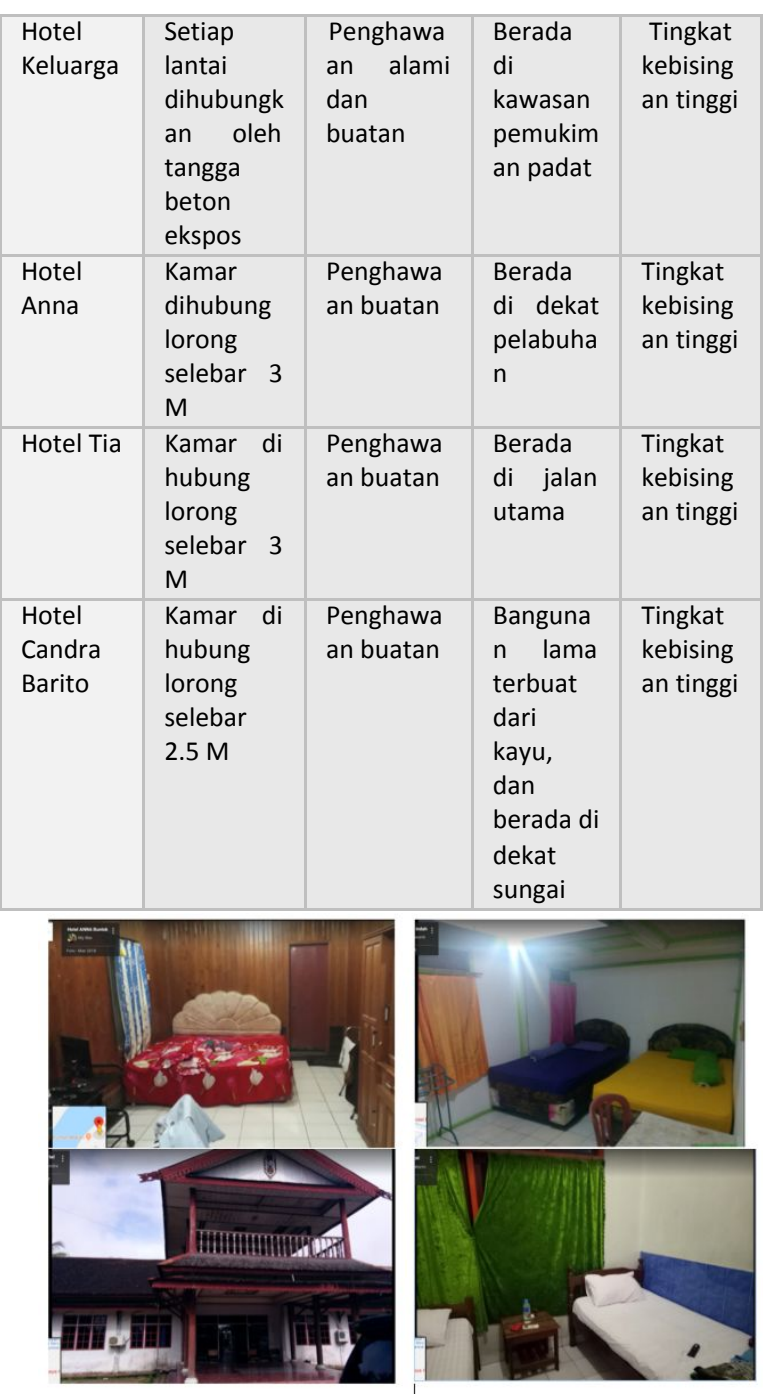

Gambar 1. Dokumentasi Penginapan di Kota Buntok

Berdasarkan hasil tinjauan tersebut, dapat disimpulkan bahwa penginapan yang ada di Kota Buntok belum dapat memenuhi kriteria kenyamanan untuk pengunjung. Sehingga keberadaan penginapan yang mampu menawarkan fasilitas lengkap serta dapat memenuhi kriteria kenyamanan dan kebersihan kepada pengunjung sangat diperlukan. Dan sebagai sebuah penginapan yang mampu mengajak pemilik-pemilik penginapan lain untuk mencontoh dan sadar akan pentingnya kebersihan bangunan.

\section{PERMASALAHAN}

Berdasarkan kebutuhan dan kenyamanan fasilitas bagi pengunjung, serta dapat memberikan identitas yang kuat akan budaya sekitar. Sehingga permasalahan arsitektural utama adalah; Bagaimana merancang guest house yang dapat 
memberi kenyamanan kepada pengunjung dengan memperhatikan identitas arsitektur rumah betang.

\section{TINJAUAN PUSTAKA}

\section{A. Pengertian Judul}

Guest House Huma Betang Indah diambil dari nama perusahaan milik owner yaitu PT Huma Betang Indah. Huma betang dalam bahasa dayak berarti rumah betang atau rumah panjang. Rumah Betang adalah rumah panjang tempat tinggal suku dayak yang didiami oleh beberapa kepala keluarga.

Guest house adalah sebuah bangunan

yang ditujukan untuk penginapan. Perbedaan guest house dengan hotel yaitu pemilik menawarkan sewa kamar harian dan bulanan, seperti kos pada umumnya namun ada pegawai kebersihan dan memiliki fasilitas yang relatif lengkap dengan harga yang terjangkau

\section{B. Jenis-Jenis Penginapan}

Berikut penjelasan macam-macam penginapan selain hotel.

- Villa adalah sebuah penginapan milik pribadi yang berada di dataran tinggi

- Motel (Motor Hotel) adalah sebuah penginapan yang melayani pelanggan transit yang menggunakan kendaraan pribadi dan menyediakan garasi.

- Losmen adalah penginapan murah dan disebut sebagai hotel melati

- Homestay merupakan sebuah penginapan dimana tamu menginap di rumah penduduk setempat, lama tinggal berbeda-beda dari satu malam hingga satu tahun tergantung keperluan. Penginapan dapat diberikan secara gratis.

- Guest House merupakan bangunan yang ditujukan sebagai tempat komersial dengan tarif yang lebih murah dibandingkan hotel, dan memiliki staf terbatas.

- Youth hotel adalah sebuah akomodasi untuk remaja yang menyediakan ranjang bertingkat

\section{Suku Dayak Kalimantan Tengah}

Dayak adalah sebutan untuk penduduk asli pulau Kalimantan. Pulau Kalimantan terdiri dari: Kalimantan Selatan dengan ibukota Banjarmasin, Kalimantan Timur dengan ibukota Samarinda, Kalimantan Barat dengan ibukota Pontianak, Kalimantan Tengah ibukota Palangkaraya, dan Kalimantan Utara dengan ibukotanya Tanjung Selor. Suku Dayak terbagi dalam 405 sub-sub suku.

Kalimantan Tengah memiliki suku dan budaya yang berbeda dari daerah lain. Suku yang banyak mendiami Kalimantan Tengah adalah Suku Dayak Bakumpai, Dayak Ngaju, Dayak Manyan dan lainnya. Suku Bakumpai mendiami daerah sepanjang pesisir Sungai Barito. Dayak Ngaju mendiami pesisir sungai Katingan, Kapuas dan Rungan. Sedangkan agamanya yang mereka anut sangat variatif. Sebelum Indonesia mengenal agama pertama yakni Hindu, Suku dayak di Kalimantan Tengah memeluk Agama yang lahir dari budaya lokal yaitu Agama Kaharingan. Menurut Mallinckrodt, Suku Dayak Bakumpai adalah Suku Dayak Ngaju yang sudah beragama Islam. Suku Bakumpai banyak bermukim di sepanjang pesisir Sungai Barito, termasuk Kota Buntok. Masyarakat Suku Dayak masih memegang teguh kepercayaan dan keyakinan mereka akan hal-hal yang berbau mistis seperti danau, pohon besar dan batu-batu memiliki penunggunya. Serta keberadaan luhur mereka.

\section{Tinjauan Rumah Betang}

Rumah betang atau disebut rumah panjang adalah tempat tinggal asli Suku Dayak Kalimantan jaman dahulu. Rumah Betang merupakan pemukiman awal yang bernilai sakral dan historis. Dan warisan kebudayaan masa lalu, kini dan masa depan. Rumah Betang terdapat di sepanjang daerah aliran sungai Barito, Mentaya, Kahayan, Katingan dan Kapuas. Betang merupakan proses awal perkembangan kota-kota di Kalimantan Tengah (Riwut, 1979).

Pengertian yang lain Betang adalah sebuah gambaran kebersamaan dalam kehidupan sehari-hari orang Dayak yang dulu tinggal di Rumah Betang. Jaman dahulu 
Rumah Betang bukan bukan hanya sebagai tempat bernaung dan berkumpul keluarga. Tetapi Rumah Betang merupakan jantung dari struktur sosial kehidupan Suku Dayak. Di dalam Rumah Betang setiap kehidupan penghuninya diatur oleh hukum adat.

Dalam Perda Provinsi Kalimantan Tengah NO. 16 Tahun 2008, menjelaskan bahwa, budaya Huma Betang atau Belom Bahadat merupakan kebiasaan yang memprioritaskan kesetaraan, kejujuran, toleransi serta taat pada hukum (hukum negara, hukum alam dan hukum adat) dan kebersamaan. Apabila mampu melaksanakan perilaku hidup Belom Bahadat, maka akan teraktualisasi dalam wujud Belum Penyang Hinje Simpe yaitu hidup rukun, berdampingan dan damai untuk kesejahteraan bersama. Belom Bahadat berarti hidup beradat, sedangkan Belom Penyang Hinje Simpe berarti hidup rukun dan damai untuk kesejahteraan bersama.

Dalam pembangunan rumah betang, walau penataan ruang bervariasi, namun ada 3 ruang yang harus dipenuhi yaitu, ruang los dan ruang bilik, ruang dapur dan karayan. Jumlah ruang bilik di rumah betang tergantung seberapa banyak orang yang di dalamnya.

Kepercayaan Suku Dayak berpengaruh besar dalam orientasi pembangunan Rumah Betang, bagian hulu harus menghadap matahari terbit dan bagian hilir harus menghadap matahari terbenam. Suku Dayak meyakini dalam menjalankan kehidupan dimulai dari terbitnya matahari dan diakhiri dengan terbenamnya matahari.

Kehidupan rumah betang juga identik dengan keberadaan sungai. Terdapat 11 sungai di Provinsi Kalimantan Tengah dengan panjang, kedalaman dan lebar yang bervariasi, seperti pada tabel berikut.

Table 2 Sungai Menurut Lebar, Kedalaman dan Panjang di Provinsi Kalimantan Tengah

\begin{tabular}{|c|c|c|c|c|}
\hline \multirow{2}{*}{ Nama Sungai } & \multicolumn{2}{|c|}{ Panjang } & \multicolumn{2}{|c|}{ Rata-rata } \\
\hline & Kilometer $(\mathrm{Km})$ & Dapat dilayari $(\mathrm{Km})$ & Kedalaman (Meter) & Lebar(Meter) \\
\hline 1. Sungai Jelai & 200 & 150 & 8 & 150 \\
\hline 2. Sungai Ant & 250 & 190 & 4 & 100 \\
\hline 3. Sungai Lamandau & 300 & 250 & 6 & 150 \\
\hline 4. Sungai Kumai & 175 & 100 & $6-9$ & 250 \\
\hline 5. Sungai Seruyan & 350 & 300 & 5 & 250 \\
\hline 6. Sungai Montaya & 400 & 270 & 6 & 350 \\
\hline 7. Sungai Katingan & 650 & 520 & $3-6$ & 250 \\
\hline 8. Sungsi Sebangau & 200 & 150 & 5 & 100 \\
\hline 9. Sungai Kahayan & 600 & 500 & 7 & 450 \\
\hline 10. Sungal Kavuas & 600 & 420 & 6 & 450 \\
\hline 11. Sungal Bartio & 900 & 700 & 14 & -500 \\
\hline
\end{tabular}

Sumber: Dinas Perhubungan, Komunikasi dan Informatika Kalimantan Tengah
Sungai yang melewati Kota Buntok Kabupaten Barito Selatan adalah Sungai Barito yang memiliki lebar kisaran 350-500 M. Kota Buntok memiliki banyak anak sungai yang mengalir langsung di dalam kota.

Selain identik dengan sungai, lantai rumah betang juga umumnya menggunakan papan kayu. Tetapi sekarang terdapat beberapa rumah betang menggunakan keramik maupun karpet. Untuk akses masuk ke rumah betang terdapat tangga atau yang disebut dengan hejan. Dahulu hejan terbuat dari batangan pohon bulat yang dibuat ruas-ruas untuk berpijak. Sesuai dengan perkembangan jaman sekarang hejan rumah betang dibuat seperti tangga pada umumnya, sehingga lebih praktis aman dan lebih mudah digunakan oleh orang banyak. Dalam pembuatan hejan ada aturan-aturan yang harus dipenuhi, seperti jumlah railing tangga yang harus ganjil antara 1 atau 3 . Suku Dayak percaya hitungan ganjil pada hejan berguna agar saat memasuki rumah pada hitungan genap yang bermakna terhindar dari malapetaka.

Lokasi pintu masuk biasanya terdapat di tengah-tengah bangunan, seolah membagi bangunan menjadi 2. Dan pintu masuk harus berada di depan los. Sedangkan untuk penempatan jendela setiap satu bilik hanya mempunyai satu jendela saja dan di setiap ruang harus mempunyai jendela sebagai lubang cahaya. Bagian atap rumah betang diekspos tanpa plafon. Bahan penutup atap biasanya menggunakan bahan sirap.

Ornamen pada rumah betang biasanya terdapat pada lisplang atap, di atas pintu ataupun jendela. Terdiri dari motif burung enggan, tumbuhan dan ular balangga. Ornamen-ornamen tersebut dipercaya untuk perlindungan terhadap roh-roh jahat, seperti :

- Ukiran Asun Bulan, biasanya terdapat di atas ambang pintu, dengan ukiran 2 orang bersalaman bermakna bahwa pemilik rumah harus ramah kepada tamu.

- Ukuran Tambarirang Maning Singkap Langit, ukiran yang biasa ditemukan di atas pintu yang menyerupai anjing melambangkan Tatun Hatuen (Raja 
Palasit) agar Hatuen tidak mengganggu penghuni

- Patung berbentuk manusia yang ada pada railing tangga, adalah simbol penjaga rumah betang agar roh-roh jahat tidak masuk ke rumah.

- Anyaman rotan bermotif Batang Garing yang terdapat di tiang agung bermakna kesejahteraan.

- Ukiran Naga Pasai ukiran pada pintu dan daun jendala melambangkan Dewa Penguasa Alam Bawah atau Bawi Jata

- Ukiran Lamantek yang bermakna kesehatan.

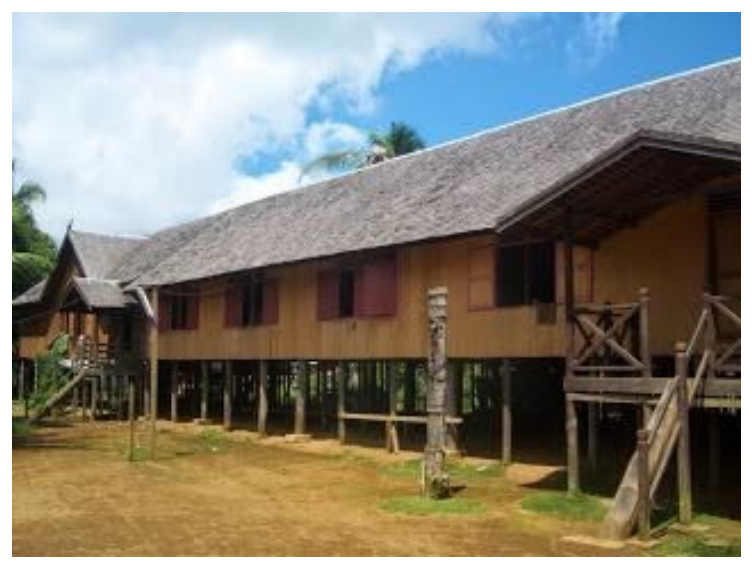

Gambar 2 Rumah Betang di Konut Sumber: Tonimono

\section{PEMBAHASAN}

\section{A. Konsep Programatik}

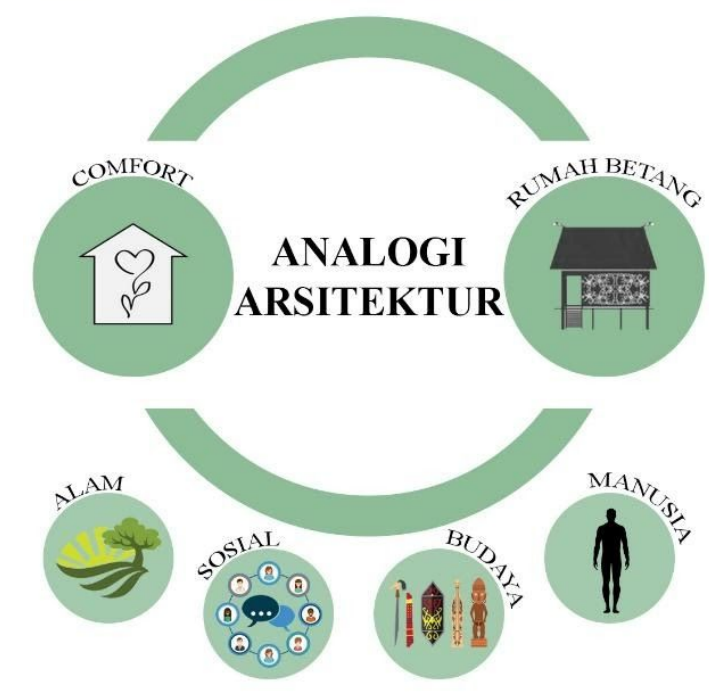

Gambar 3 Konsep Programatik

Konsep dari perancangan Guest House Huma Betang Indah menerapkan konsep yang dapat memenuhi elemen-elemen alam, sosial, budaya dan manusia. Dengan menggunakan rumah betang sebagai acuan sehingga digunakan konsep analogi arsitektur. Analogi arsitektur merupakan konsep yang dimana menerapkan kesamaan dengan objek yang dipilih secara visual, dapat berupa bentuk, bangunan lain, alam, benda olahan manusia dan pemikiran atau ideologi seseorang. Hal terpenting dalam analogi arsitektur adalah pemilihan objek yang akan dianalogikan. Sesuai dengan permasalahan pada rancangan guest house objek yang akan dianalogikan adalah rumah betang, rumah adat suku dayak.

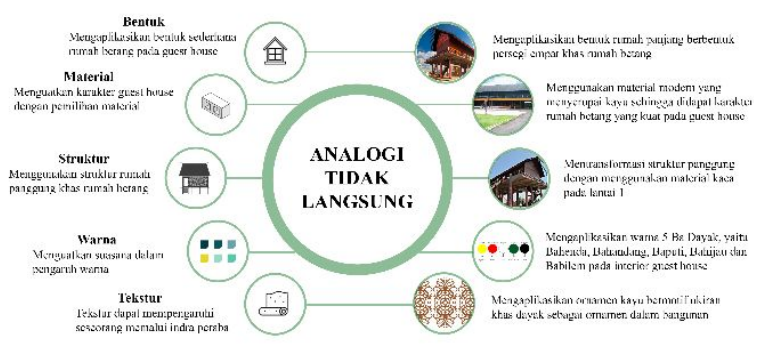

Gambar 4 Analogi Tidak Langsung

\section{B. Konsep Desain}

\section{Konsep Bentuk}

Konsep bentuk pada bangunan diambil dari pengolahan bentukan rumah betang Suku Dayak yang selalu berbentuk panggung dan panjang. Karena rumah betang di bangun di pinggir sungai, bentukan ini diyakini oleh Suku Dayak dapat melindungi rumah dari banjir. Dan Untuk melindungi penghuninya dari binatang buas dan musuh. berdasarkan analisis bentuk rumah betang, rumah betang memiliki tinggi antara $3 \mathrm{~m}$ hingga $5 \mathrm{~m}$. panjang rumah betang mulai dari $30 \mathrm{~m}$ sampai $150 \mathrm{~m}$ dengan lebar $30 \mathrm{~m}$. Karena bentuknya yang besar maka pada perancangan guest house ini bangunan dipecah menjadi 2 bangunan sehingga secara keseluruhan guest house dapat menyatu dengan lingkungan sekitar. View. Berdasarkan hasil analisis tersebut terdapat hasil pembagian zoning berupa sungai, guest house dan hutan. Untuk gubahan bentuk bangunan yang digunakan untuk Guest House Huma Betang Indah adalah bentuk persegi panjang sesuai dengan rumah betang. 


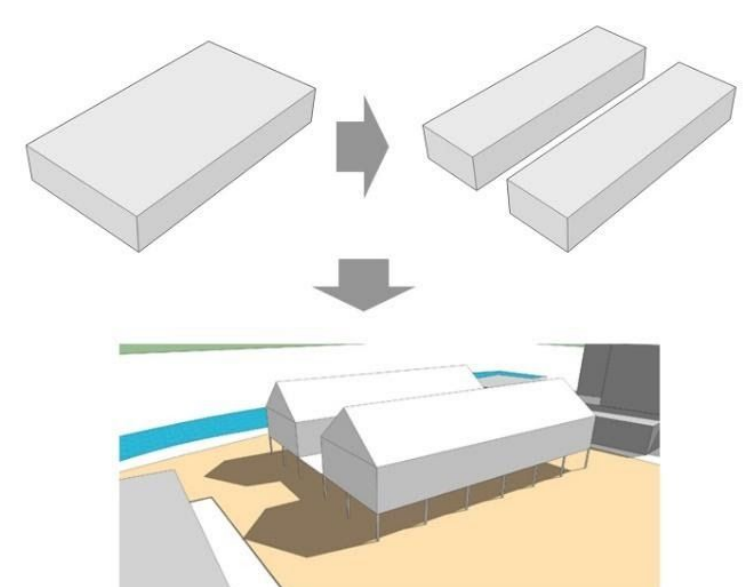

Gambar 5 Analisa Bentuk, 2019

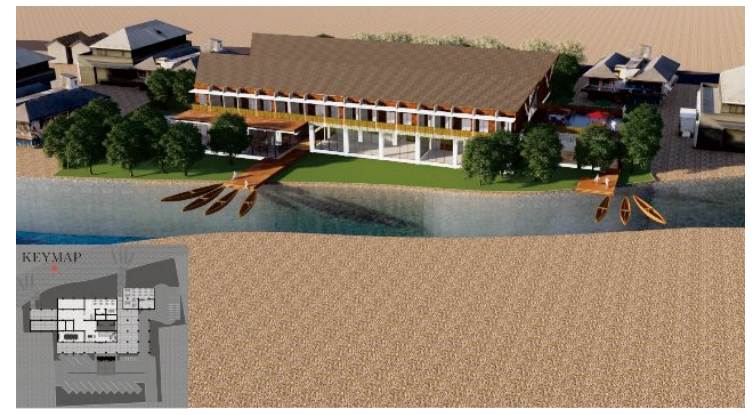

Gambar 6 Desain Bentuk Guest House

\section{Konsep Fasade Bangunan}

Fasade bangunan terbuat dari kisi-kisi kayu yang diteruskan menjadi pergola pada balkon depan. Pada kisi-kisi kayu terdapat ornamen talawang. Yang zaman dahulu digunakan oleh suku dayak untuk melindungi diri serangan musuh. Ornamen talawang pada guest house selain memiliki nilai budaya dan estetis juga dapat diinterpretasikan sebagai perisai untuk membentengi tamu guest house yang menginap.

Pintu masuk utama guest house diletakkan di tengah bangunan sesuai dengan aturan pembangunan rumah betang.

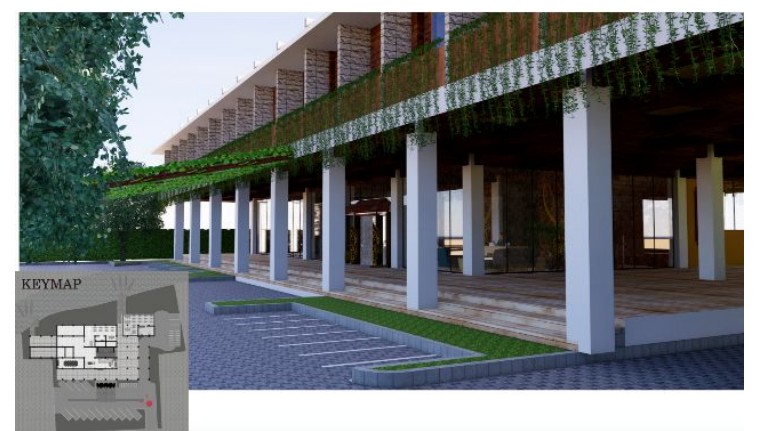

Gambar 7 Fasade Guest House

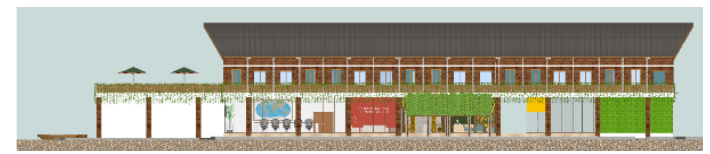

Gambar 8 Tampak Depan

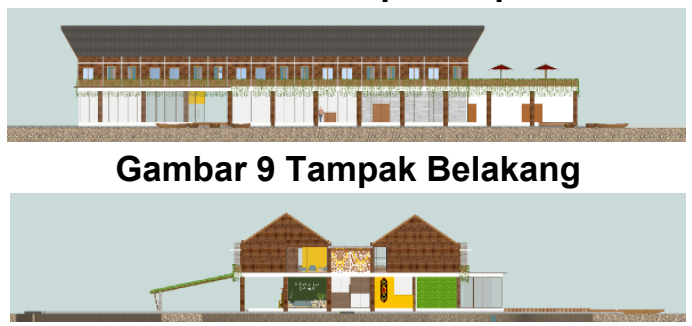

Gambar 10 Tampak Kanan

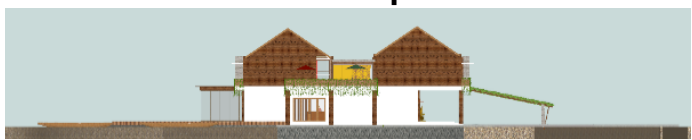

Gambar 11 Tampak Kiri

3. Konsep Material, Warna dan Tekstur

Guest house memilih menggunakan material kayu sebagai elemen material bangunan. Warna hijau digunakan sebagai warna dasar bangunan karena Suku Dayak memiliki kepercayaan warna hijau atau bahijau memiliki makna kehidupan, pembangunan dan perdamaian yang diinspirasi oleh warna tanaman yang ada di sekitar mereka. Selain bahijau, warna lain dari 5 ba juga akan diterapkan pada guest house.

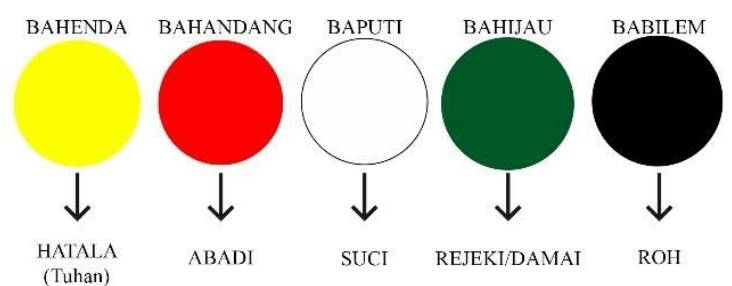

Gambar 125 Ba Suku Dayak 4. Konsep Tata Ruang Luar dan Dalam

Konsep tata ruang terbagi dari area hutan - guest house - sungai

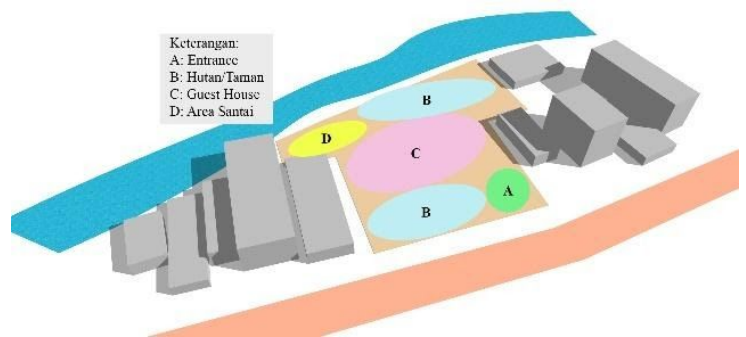

Gambar 13 Konsep Tata Ruang 

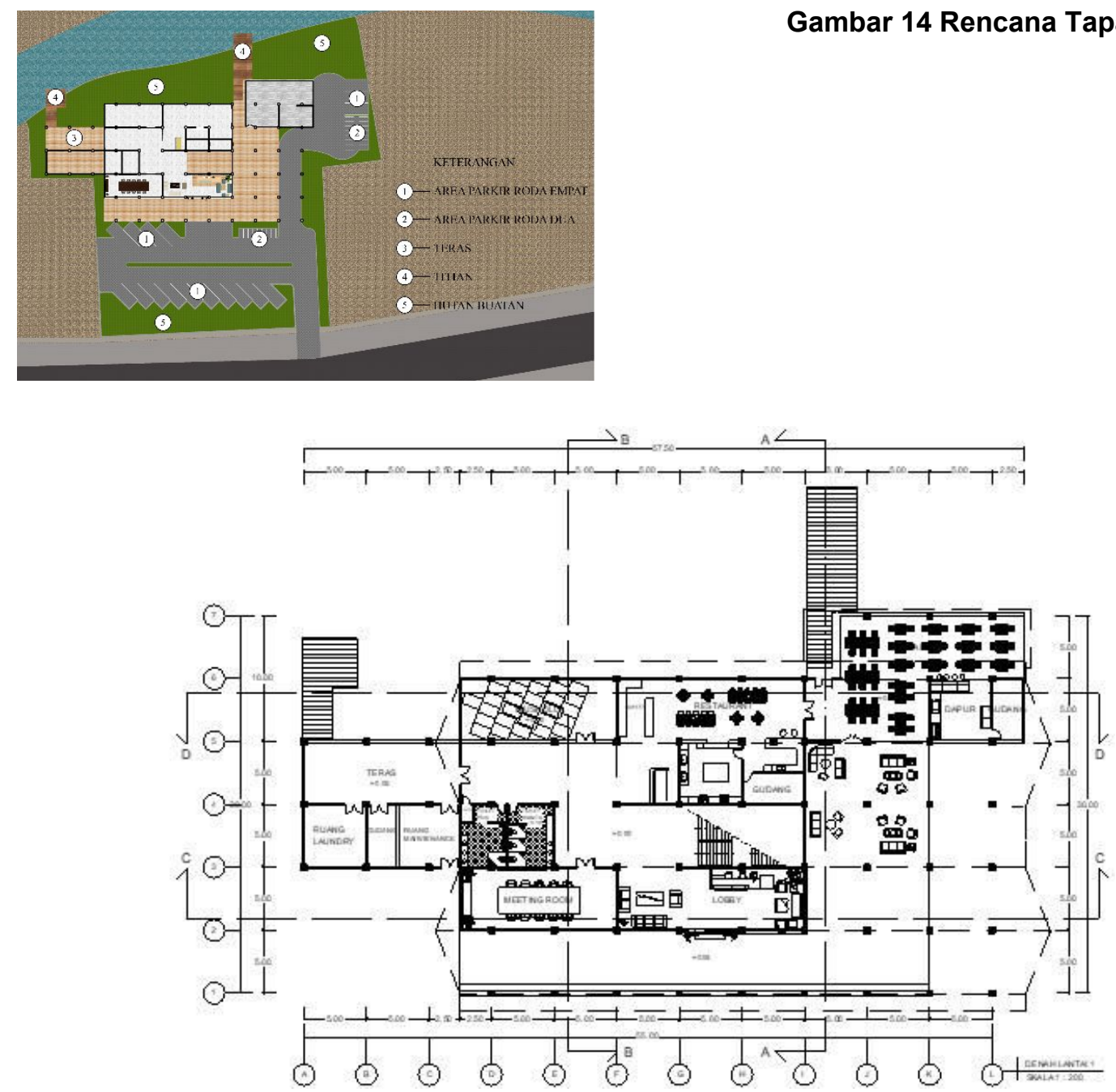

\section{Gambar 15 Denah Lantai 1}

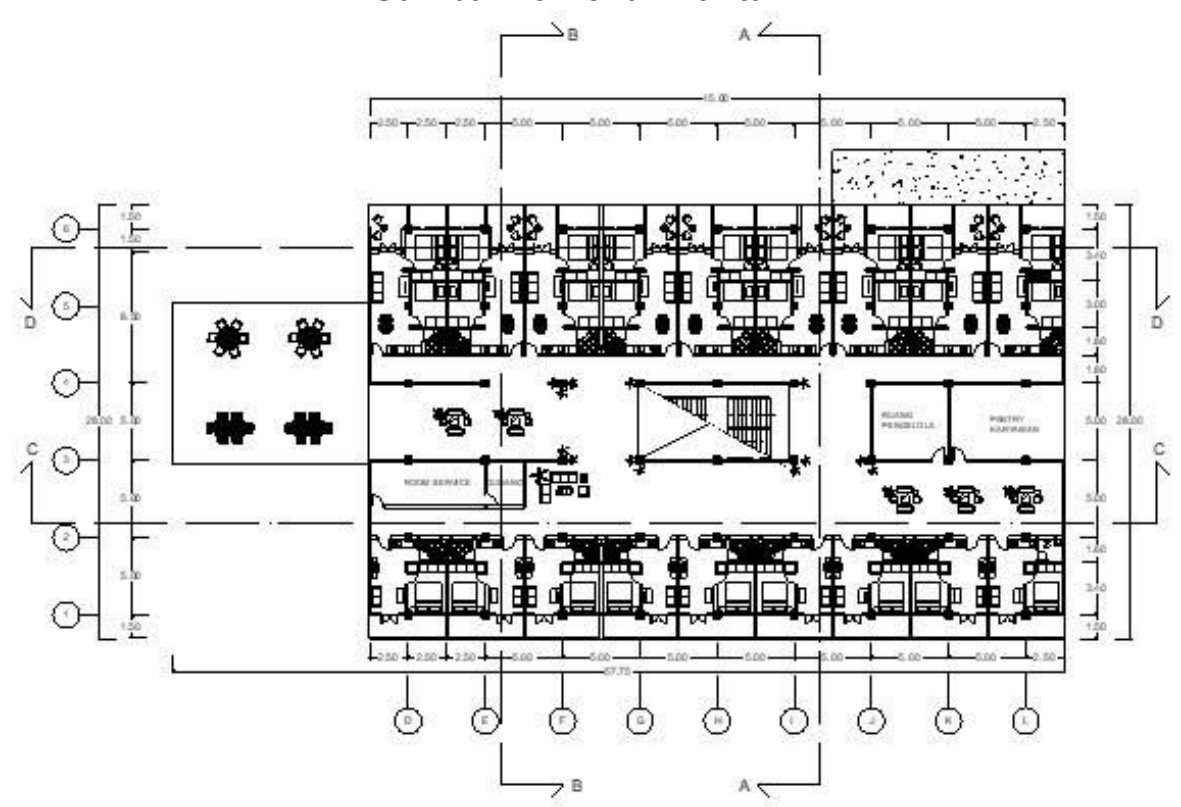

Gambar 16 Denah Lantai 2

\section{Konsep Utilitas}

- Konsep Jaringan Air Bersih 


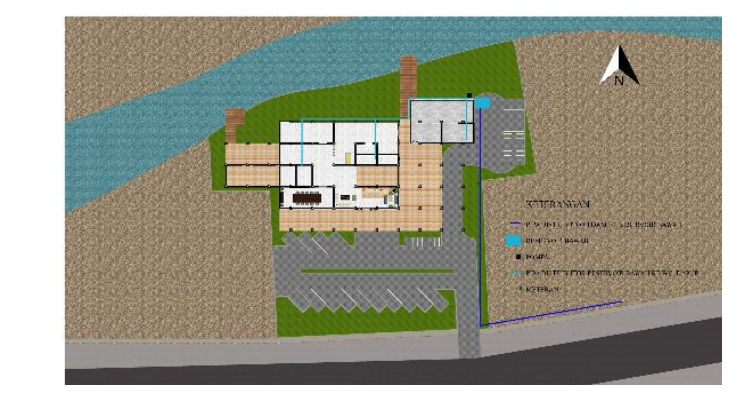

Gambar 17 Utilitas Air Bersih

o Konsep Jaringan Air Kotor

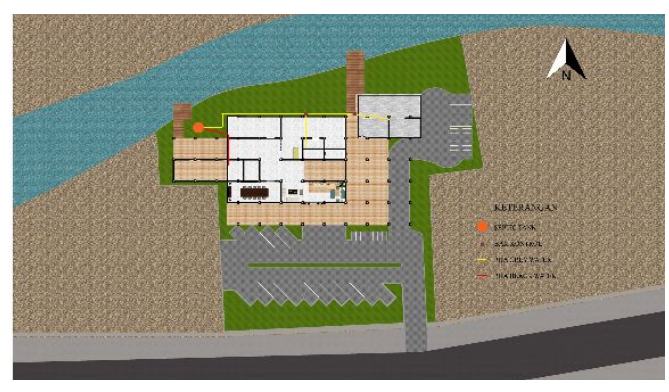

Gambar 18 Utilitas Air Kotor KESIMPULAN

Kota Buntok merupakan ibukota Kabupaten Barito Selatan. Kota Buntok terletak di pinggiran Sungai Barito dan menghubungkan Kota Palangkaraya dan kabupaten-kabupaten yang berada di sepanjang Sungai Barito seperti: Barito Timur, Barito Utara, hingga kabupaten yang berada di Kalimantan Selatan seperti Hulu Sungai Utara, Kabupaten Tabalong dan sebagainya. Identitasnya yang menjadi kota penghubung menjadikan kota ini ramai didatangi oleh wisatawan sehingga keberadaan penginapan sangat diperlukan.

Permasalahan yang diangkat adalah bagaimana merancang Guest House Huma Betang Indah yang dapat memenuhi kebutuhan wisatawan serta memiliki identitas budaya dayak yang kuat. Untuk menjawab permasalahan tersebut digunakan pendekatan analogi langsung. Yang menjadi objek amatan adalah rumah adat Suku Dayak yaitu Rumah Betang. Dari hasil analisis menggunakan analogi langsung didapat bahwa guest house harus memiliki ikatan yang kuat dengan alam.

Lokasi site yang berada di tepi sungai dan kebutuhan guest house yang berikatan kuat dengan alam maka digunakan konsep analogi arsitektur. Analogi arsitektur merupakan konsep dimana menerapkan kesamaan dengan objek yang dipilih secara visual, dapat berupa bentuk, bangunan lain, alam, benda olahan manusia dan pemikiran atau ideologi seseorang. Hal terpenting dalam analogi arsitektur adalah pemilihan objek yang akan dianalogikan. Sesuai dengan permasalahan pada rancangan guest house objek yang akan dianalogikan adalah rumah betang, rumah adat suku dayak. Dari konsep analogi arsitektur didapat pembagian zoning berupa hutan guest house - sungai.

Lanskap depan tapak guest house akan terdiri dari pohon-pohon peneduh yang akan membuat ilusi hutan. Adanya hutan di depan bangunan membuat guest house akan terlindungi dari pandangan jalan dan memberi kesan private. Sedangkan area belakang guest house adalah sungai yang dapat dikembangkan menjadi area rekreasi dan area santai pengunjung.

Pada fasade bangunan akan diterapkan prinsip-prinsip rumah betang dan ornamen-ornamen khas Suku Dayak. Pada bagian penggunaan sistem struktur disesuaikan dengan kondisi eksisting, untuk struktur pondasi digunakan pondasi tapak. Pada struktur badan menggunakan tiang kolom beton dengan rangka atap pelana yang sesuai dengan iklim dan cuaca di Kota Buntok.

\section{DAFTAR PUSTAKA}

BPS. (2015). Jumlah Penduduk di Kabupaten Barito Selatan. Diambil kembali dari BPS: https://barselkab.bps.go.id/

Hamidah, Garib. (2014). Studi Arsitektur Rumah Betang Kalimantan Tengah

Johansen, Poltak. (2014). Arsitektur Rumah Betang (Radakng) Kampung Sahamp. Pontianak: Balai Pelestarian Nilai Budaya

Radian, Endy. (2017). Hunian Rumah Betang (Agregasi Budaya. Alkimia Arsitektur Dayak Demi Fundamentalisme Arsitektur Nusantara). Surabaya: Institut Teknologi Sepuluh November 